\title{
Quỹ Vaccine phòng chống Covid-19: Một mốc lịch sử kinh tế đương đại
}

Hồ Mạnh Toàn, Nguyễn Thanh Thanh Huyền (Trung tâm ISR, Trường ĐH Phenikaa) 07/06/2021 11:02

Quỹ Vaccine phòng chống Covid-19 của Chính phủ do Thủ tướng Phạm Minh Chính lãnh đạo đã phản ánh rất sát việc thiết kế toàn diện, có tính chiến lược đối với công cuộc xây dựng kinh tế đường dài, dựa trên cấu trúc vi mô có khả năng tương tác hiệu quả cao với các tâng lớp cư dân trong xã hội, đặc biệt là giới doanh nghiệp.

Tháng 5 và tháng 6-2021 chứng kiến làn sóng Covid-19 thứ tư tác động lên xã hội Việt Nam, thách thức nội các Chính phủ của tân Thủ tướng Việt Nam Phạm Minh Chính. Đại dịch Covid-19 tác động sâu sắc lên nền kinh tế từ năm 2020 sang giữa năm 2021, và dự kiến còn tiếp diễn.

Trong rất nhiều quyết sách kinh tế-xã hội tầm quốc gia, Chính phủ và Thủ tướng đặt nghị sự lớn cho việc xử lý rốt ráo Covid-19, với chủ trương bao quát "5K + Vaccine", và ngày 26-5-2021, Thủ tướng đã có Quyết định số 779 về việc thành lập Quỹ Vaccine phòng chống COVID-19 do Bộ Tài chính quản lý. Ngày 5-6-2021, Quỹ Vaccine phòng chống Covid-19 chính thức khai trương và đón nhận sự hưởng ứng của đông đảo tầng lớp dân cư, bao gồm cả giới chính trị, doanh nhân, trí thức, tôn giáo và các hộ gia đình, trên khắp cả nước.

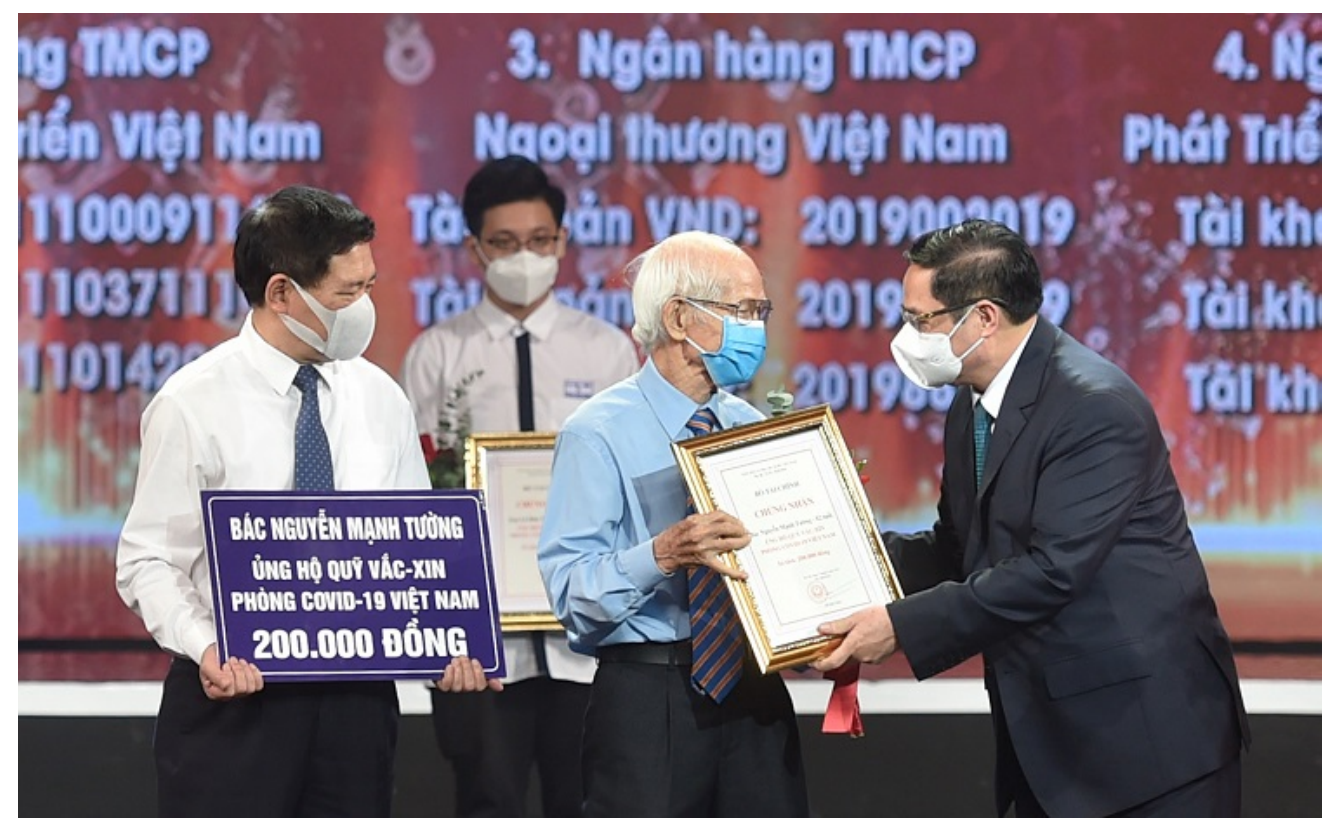


Thủ tướng Phạm Minh Chính trao chứng nhận, hoa cảm ơn ông Nguyễn Mạnh Tường, 82 tuổi, cán bộ hưu trí ngành đường sắt. Ảnh VGP

Trong sự kiện quan trọng được nhiều tờ báo tổng thuật trực tiếp này, Thủ tướng Phạm Minh Chính nêu lại sự việc, năm 1945, toàn dân đồng lòng hưởng ứng Quỹ độc lập theo lời kêu gọi của Chủ tịch Hồ Chí Minh, góp phần thiết thực cho cuộc kháng chiến kiến quốc thành công.

Việc dẫn chiếu tới sự kiện lịch sử của Quỹ Độc lập cho thấy Thủ tướng Phạm Minh Chính đánh giá chính xác tầm mức quan trọng của việc chiến thắng đại dịch Covid-19, và ích lợi to lớn của chiến thắng này đối với công cuộc phát triển kinh tế quốc dân trong thời kỳ tới đây. Đồng thời, ông cũng đặt lên trước tiên, trên hết sự đoàn kết, hiểu biết, minh bạch thông tin và hợp tác của các tầng lớp dân chúng trong xã hội với Chính phủ, Nhà nước và Đảng trong nhiệm vụ nặng nề và thách thức ngay trong những ngày đầu của Chính phủ mới.

Cách đánh giá sâu sắc và bao quát của Chính phủ có chỉ dấu từ hoạt động nghiên cứu từ 13 năm trước, khi Thủ tướng còn đang soạn thảo cuốn Kinh tế Việt Nam: Thăng trầm và đột phá. Trong đó, sự kiện Quỹ Độc lập do Chủ tịch Hồ Chí Minh được sớm nhắc đến với ý nghĩa lịch sử to lớn, tại bối cảnh đầy cam go thử thách của nhà nước Việt Nam Dân chủ Cộng hòa non trẻ, ở những trang 52-56 của cuốn sách.

\section{2 Đấu tranh giành độc lập tiền tệ}

Tài chính của quốc gia độc lập non trẻ được gây dựng với ngân khố gẩn như trống rỗng. Chính quyển cách mạng chỉ tiếp quản được kho bạc với 1.230.720 đồng, trong đó có 586.000 đống tiển rách. Việc phát hành giấy bạc Đông Dương vẵn nằm trong tay thực dân Pháp. Nguốn thu ngân sách từ thuế thì đã bãi bỏ trong tháng $8 / 1945$, sau đó có khôi phục lại một số sắc thuế, nhưng không đáng kể.

Khó khăn lớn tới mức thực dân Pháp tin rằng Việt Minh nếu chưa chết vì một cuộc tấn công quân sự thì sẽ chết vì kiệt quệ tài chính. Chính ở thời điểm đó, niểm tin của đổng bào Việt $\mathrm{Nam}$ trong và ngoài nước

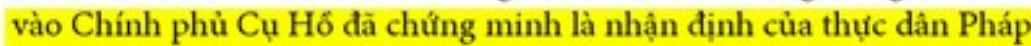
hoàn toàn sai lẩm. Quyên góp của Quỹ độc lập được thành lập ngày 4/9/1945 (hai ngày sau khi chính thức khai sinh nước Việt Nam Dân chủ Cộng hòa) và Tuân lể Vàng bắt đẩu từ ngày 16/9/1945 đã bổ sung nguônn lực tài chính tương đương một năm thu thuế thân và thuế điển toàn quốc dưới thời thực dân Pháp.

Để thấy nguốn lực ủng hộ của đổng bào lớn tới mức nào, có thể so sánh với một số khoản chi tiêu lớn của Chính phủ cách mạng. Bộ Tài chính chi 1.450 .000 đống Đông Dương cho việc sửa chủa quốc lộ 1 (ngày 27/9/1946), chi 1.302.000 đông Đông Dương để sửa chưa câu Guột và cẩu Ninh Bình (ngày 10/9/1946), chi 2.200.000 đồng Đông Dương để tu sưa đường sá tại thủ đô Hà Nội (ngày 25/9/1946)...

Trong Tuẩn lễ Vàng các tâng lớp nhân dân cả nước đã hưởng ứng và đóng góp $370 \mathrm{~kg}$ vàng và hơn 20 triệu đônng Đông Dương cho Quỹ dộc lập và $Q u y ̃$ dảm phu quốc phòng. Nếu qui đổi thành vàng và tính 


\title{
theo thời giá tháng 8/2008, giá trị đóng góp tương đương hơn 6.100 tỷ
}

Đoạn trích từ sách Kinh tế Việt Nam: Thăng trầm và đột phá (Nxb Chính trị Quốc gia, Hà Nội, 2009), trang 55. Nguồn: Google Books

Từ quan điểm nghiên cứu chiều dài lịch sử kinh tế, quan điểm trường kỳ với sức khỏe và hạnh phúc xã hội trong sự nghiệp phát triển đất nước của Thủ tướng đã được đặt trong bối cảnh cụ thể của thời kỳ 2020-2021. Cách nhìn biện chứng và phản ánh động học thay đổi kinh tế-xã hội này cũng phản ánh tư duy của Thủ tướng từ bài nghiên cứu Bối cảnh tài chính Việt Nam 1997-1998 và 2007-2008: Khoảng cách và biến đối, ngay trong thời kỳ kinh tế thế giới khủng hoảng, và nền kinh tế Việt Nam lúc đó chịu tác động tiêu cực nặng nề.

\section{Bối cảnh tài chinh Việt Nam 1997-1998 và 2007-2008: khoảng cách và biến đổi}

\author{
PHAM MINH CHÍNH \\ VƯ̛̛NG QUÂN HOȦNG
}

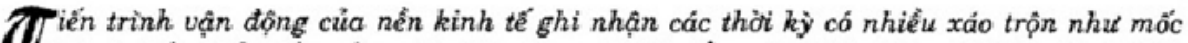

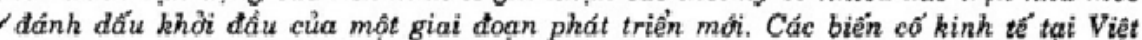
Nam trong nhüng năm 1997-1998 chịu ảnh huơng lan truyền từ khủng hoảng tài chính-tiền

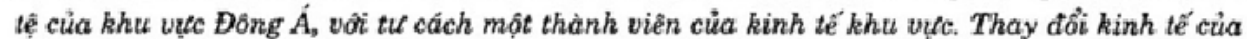
một thập kỷ sau, 2007-2008, diễn ra cùng lúc vời khủng hoảng tín dụng toản cẩu, bắt nguồn

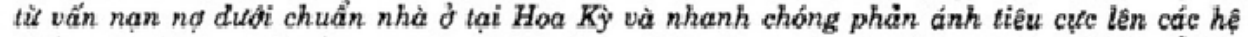
thống tài chính quốc tể, trong đố có Việt Nam. Bầi viêt tộp trung phan tích các biến đối rát

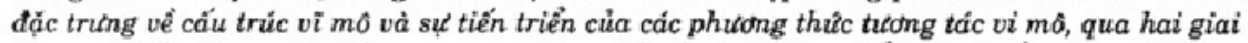

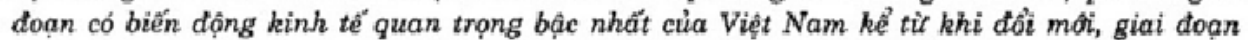

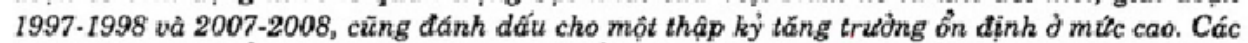

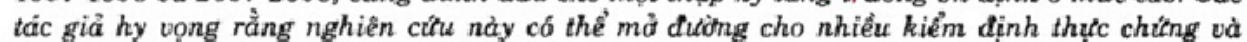

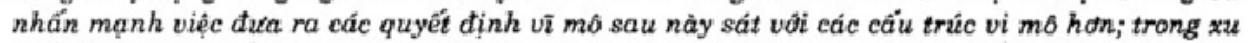

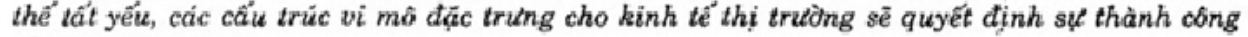
của lưa chan vĩ mô.
\end{abstract}

Hình ảnh tóm tắt nghiên cứu xuất bản trên Nghiên cứu Kinh tế (Viện Kinh tế, Viện Hàn lâm KHXH Việt Nam) năm 2008. Nguồn: Trích xuất sưu tầm từ Internet

Trong nghiên cứu, có thể nhận ra tư tưởng chủ đạo, bao quát:

1. Mở đường cho các kiểm định thực chứng.

2. Các quyết sách vĩ mô cần được điều chỉnh sát với thực tế của cấu trúc vi mô.

3. Các đặc trưng cấu trúc vi mô trong vận hành kinh tế thị trường sẽ quyết định thành công của lựa chọn vĩ mô.

Như thế, Quỹ Vaccine phòng chống Covid-19 của Chính phủ do Thủ tướng Phạm Minh Chính lãnh đạo phản ánh rất sát việc thiết kế toàn diện, có tính chiến lược (không hề mang tính thời điểm hay tình thế) đối với công cuộc xây dựng kinh tế đường dài, dựa trên cấu trúc vi mô có khả năng tương tác 
hiệu quả cao với các tầng lớp cư dân trong xã hội, đặc biệt là giới doanh nghiệp. Quan điểm về các giao dịch thị trường, giá cả, số lượng và chủng loại vaccine của Thủ tướng được phản ánh rõ tại phiên họp tổng kết điều hành Chính phủ ngày 31-5-2021, trong đó nêu rõ:

"Chiến lược vaccine tổng thể, toàn diện, hiệu quả; đẩy nhanh tiến độ tiếp cận các nguồn cung vaccine đa dạng thông qua các biện pháp ngoại giao, kinh tế, quần chúng và các biện pháp đặc biệt khác. Giao các Bộ: Y tế, Công an, Quốc phòng, Khoa học và Công nghệ và Ngoại giao đẩy nhanh hơn nữa việc tìm nguồn, mua vaccine và tiến độ nghiên cứu, sản xuất vaccine ở trong nước, tìm phương án tiếp nhận, chuyển giao công nghệ sản xuất vaccine của nước ngoài... "

Từ những dữ liệu trên cơ sở khoa học chắc chắn, và hành động dứt khoát, chú trọng hiệu lực bộ máy-hiệu quả kinh tế của Chính phủ, chúng ta có thể tin tưởng Việt Nam sẽ chiến thắng trong giai đoạn quyết định quan trọng, tạo nên dấu mốc lịch sử cho cả Quỹ vaccine mới ra đời và công cuộc chiến đấu chống đại dịch, cũng như động lực phát triển kinh tế-xã hội Việt Nam sau thời kỳ Covid-19.

\section{Tài liệu tham khảo:}

1. Chính, P. M., \& Hoàng, V. Q. (2009). Kinh tế Việt Nam: Thăng trầm và đột phá. Nxb Chính trị Quốc gia, Hà Nội.

2. Chính, P. M., \& Hoàng, V. Q. (2008). Bối cảnh tài chính Việt Nam 1997-1998 và 2007-2008: Khoảng cách và biến đối. Nghiên cứu Kinh tế, 48(7), 3-24. 